\title{
Nawani And Nukoni Applications for Supporting Small and Medium Micro Enterprises in Gunungkidul District
}

\author{
Asih Pujiastuti ${ }^{1}$, Astika Ayuningtyas ${ }^{2}$, Anggraini Kusumaningrum $^{3}$, Adetya Dyas Saputra ${ }^{4}$ \\ 1,2,3,4 Sekolah Tinggi Teknologi Adisutjipto \\ Email: asihpuji@stta.ac.id
}

Received: Oktober 23, 2020; Accepted : January 14, 2021; Published : May 1, 2021

\begin{abstract}
ABSTRCT
Micro, Small and Medium Enterprises (MSME) can be defined as a productive business that can be owned by individuals or business entities and has met the criteria as a micro business. UMKM is one of the spearheads of an independent economy that has great development potential, so that the existence of MSMEs can strengthen the people's economy. One area that has a lot of MSMEs is Gunungkidul Regency which is located in the Special Region of Yogyakarta. There are many obstacles in the UMKM business in Gunungkidul Regency, one of which is in marketing and product management. Support from the technological side is needed to increase the pace of the MSME economy. One form of technology support is an inventory application that can help MSMEs in managing product stocks and supporting product marketing. Applications named Nawani and Nukoni can make it easier for MSME business players in marketing products. Nawani functions to market UMKM products and perform stock management, while Nukoni functions as a catalog for MSME products. Based on the test obtained using a Likert Scale, Nawani has a score of $78.8 \%$ for the Function Test and the UI / UX Test of $69.6 \%$, while Nukoni has a score of $85.3 \%$ for the Function Test and the UI / UX Test for 70.2\%, so that both applications are running and suitable for use by both parties.
\end{abstract}

Keywords: MSME, inventory application, Nawani, Nukoni, Android, Gunungkidul

\section{ABSTRAK}

Usaha Mikro Kecil dan Menengah (UMKM) dapat diartikan sebuah usaha produktif yang dapat dimiliki perorangan atau badan usaha dan telah memenuhi kriteria sebagai usaha mikro. UMKM merupakan salah satu ujung tombak perekonomian yang mandiri yang memiliki potensi perkembangan yang besar, sehingga keberadaan UMKM dapat memperkuat perekonomian rakyat. Salah satu daerah yang mempunyai UMKM yang banyak adalah Kabupaten Gunungkidul yang terletak di Daerah Istimewa Yogyakarta. Kendala pada bisnis UMKM di Kabupaten Gunungkidul sangat banyak,salah satunya yaitu pada pemasaran dan manajemen produk. Dukungan dari sisi teknologi sangat diperlukan untuk meningkatkan laju perekonomian UMKM. Bentuk dukungan dari sisi teknologi, salah satunya adalah aplikasi inventaris yang dapat membantu UMKM dalam pengelolaan stok produk dan mendukung pemasaran produk. Aplikasi yang bernama Nawani dan Nukoni dapat memudahakan pelaku bisnis UMKM dalam memasarkan produk. Nawani berfungsi untuk memasarkan produk UMKM serta melakukan manajemen stok, sedangkan Nukoni berfungsi sebagai katalog produk UMKM. Berdasarkan pengujian diperoleh Menggunakan Skala Likert, Nawani memiliki skor Uji Fungsi sebesar 78,8\% dan Uji UI/UX sebesar 69,6\% sedangkan Nukoni memiliki skor Uji Fungsi sebesar $85,3 \%$ dan Uji UI/UX sebesar 70,2\%, sehingga kedua aplikasi tersebut berjalan dan cocok digunakan oleh kedua belah pihak.

Kata Kunci : UMKM, aplikasi inventaris, Nawani, Nukoni, Android, Gunungkidul

\section{Latar Belakang Masalah}

Seiring dengan produktivitas manusia yang semakin meningkat dan perkembangan jaman yang semakin maju, kebutuhan untuk berkomunikasi dan bertukar data dengan cepat dan mudah menjadi sebuah tuntutan dan mobile smartphone adalah salah satu solusinya. Menurut kamus Bahasa Inggris, mobile berarti dapat bergerak dengan bebas dan mudah, tetapi dapat pula diartikan sebagai sebuah teknologi digital yang dapat dibawa atau digerakan tanpa menggunakan kabel (wireless) [1]. Terlihat bahwa trend ke depan adalah setiap teknologi harus terkoneksi satu sama lain sehingga tercipta suatu konvergensi [2]. Berbagai jenis aplikasi yang ditawarkan bukan hanya untuk keperluan komunikasi saja tetapi telah merambah untuk seluruh bidang kehidupan dari pendidikan, perbankan, hiburan seperti game, music dan film, hingga di bidang perdagangan, dari lapisan atas seperti bagian akuntan sampai lapisan terbawah, yaitu pada unit Usaha Mikro Kecil dan 
Menengah (UMKM). UMKM merupakan usaha produktif untuk berkembang yang mendukung ekonomi nasional [3][4].

UMKM Gunungkidul merupakan salah satu UMKM yang sedang berkembang dan mendapat perhatian pemerintah yang ada di Pulau Jawa, khususnya di Daerah Istimewa Yogyakarta. Pengembangan UMKM daerah mempunyai peranan yang sangat penting untuk pertumbuhan ekonomi bagi masyarakat. Untuk menjamin supaya UMKM dapat berkembang baik, maka diperlukan dukungan dari sisi teknologi, salah satunya adalah aplikasi inventaris yang dapat membantu UMKM dalam pengelolaan stok produk dan mendukung pemasaran produk. Di sisi lain, juga perlu dibuat aplikasi untuk konsumen yang digunakan untuk mencari produk UMKM yang terintegrasi dengan aplikasi inventaris. Terintegrasi yang dimaksud adalah saling terhubungnya data produk dan informasi UMKM ada pada aplikasi inventaris yang akan diberi nama Nawani dengan aplikasi konsumen yang akan diberi nama Nukoni secara realtime.

Banyak sekali cara untuk memudahkan pembuatan aplikasi inventaris maupun aplikasi katalog produk, namun tidak semua memiliki performa dan kompleksitas yang tinggi dengan kemudahan dalam pengembangannya. Aplikasi inventaris merupakan aplikasi dalam hal perniagaan, sehingga dibutuhkan performa yang tinggi dalam pengolahan data serta kompleksitas fitur yang dapat digunakan untuk memudahkan pengguna baik dari sisi pelaku bisnis UMKM maupun konsumen. Google menawarkan sebuah platform Backend as a Service (BaaS) yang diberi nama Firebase yang memiliki fitur utama yaitu Realtime Database [5][6][7]. Firebase memiliki kompleksitas fitur dan fungsi dengan performa yang tinggi, serta kemudahan dalam penggunaannya baik dari segi pengembangan aplikasi maupun penggunaan fitur dalam aplikasi yang dapat memudahkan pelaku bisnis UMKM di Kabupaten Gunungkidul.

Penelitian sebelumnya telah ada juga yang membanguan sebuah aplikasi untuk membantu UMKM dalam pengelolaan stok produk dan mendukung pemasaran produk, namun berbasis teknologi Web dan hanya terdapat pada satu kecamatan saja di Wilayah Gunungkidul [3]. Oleh sebab itu, pada penelitian ini akan membuat sistem berbasis Android untuk memanajemen produk, salah satunya adalah aplikasi inventaris yang dapat membantu UMKM dalam pengelolaan stok produk dan mendukung pemasaran produk. Aplikasi yang bernama Nawani dan Nukoni dapat memudahakan pelaku bisnis UMKM dalam memasarkan produk. Nawani berfungsi untuk memasarkan produk UMKM serta melakukan manajemen stok, sedangkan Nukoni berfungsi sebagai katalog produk UMKM. Aplikasi ini dapat memudahkan pelaku bisnis UMKM dalam melakukan transaksi produknya serta menjangkau konsumen dengan luas.

\section{Metodologi Penelitian}

Metodologi penelitian yang digunakan pada rancang dan bangun Aplikasi Nawani dan Nukoni ini berfokus pada satu kasus secara insentif dan mendetail. Adapun tahapannya antara lain:

\subsection{Pengumpulan Data}

Tahapan ini dilakukan untuk mengetahui permasalahan lebih lengkap, metode yang digunakan pada tahapan ini ada 3 (tiga) yaitu kepustakaan, observasi dan wawancara. Observasi dilakukan dengan cara mengamati kegiatan penggunaan aplikasi dari sisi pelaku bisnis maupun sisi konsumen yang ingin mencari produk yang diinginkan di kawasan Gunungkidul. Sedangkan metode wawancara dilakukan oleh penulis pada saat melakukan pengembangan maupun pengujian aplikasi langsung kepada pengguna, yaitu pelaku bisnis UMKM serta konsumen yang merupakan warga asli Gunungkidul dalam penelitian ini di fokuskan pada UMKM Kecamatan Patuk yang bantu oleh Kantor Badan Kerjasama Antar Desa (BKAD) Kecamatan Patuk Kabupaten Gunungkidul. Hasil yang diperoleh dari pengumpulan data berupa data- data yang dibutuhkan dalam proses rancang bangun aplikasi UMKM dan Mitra UMKM. Adapun data-data tersebut adalah :

1) Data Desa : berupa nama 11 desa di kecamatan Patuk Kabupaten Gunungkidul.

2) Data Pemilik UMKM : berupa Nama, alamat, no tlp

3) Data produk UMKM : berupa nama produk, harga dan keterangan produk

Tabel 1. Contoh Data Produk UMKM Kabupaten Gunungkidul

\begin{tabular}{clcc}
\hline No. & \multicolumn{1}{c}{ Produk Unggulan } & Lokasi & Nomor WA \\
\hline 1 & Galery 99 (kerajinan logam) & Patuk & 0822266789XX \\
2 & Batik Amarilis & Salam & $0812272080 X X$ \\
3 & Kembang Goyang & Noro oro & $0878393733 X X$ \\
4 & Coklat Gunkid Pak Paryanto & Bunder & 0821371211 XX \\
5 & Criping Pisang & Semoyo & $0856411300 X X$ \\
6 & Bolu Jadul & Nglanggeran & $0819040408 X X$
\end{tabular}


Nawani And Nukoni Applications for Supporting Small and Medium Micro Enterprises in Gunungkidul District

\begin{tabular}{clcc}
7 & Pop Corn & Pengkok & $0877396675 X X$ \\
8 & Kripik Bunga Durian & Patuk & $0882250727 \mathrm{XX}$ \\
9 & Keripik Pisang, dan Singkong & Putat & $0879993733 \mathrm{XX}$ \\
10 & Criping Tales & Bunder & $0883450727 \mathrm{XX}$ \\
11 & Produsen tahu & Nglegi & $0812252110 \mathrm{XX}$ \\
\hline
\end{tabular}

\subsection{Analisis Perancangan Sistem}

Pada tahap ini dilakukan perancangan menggunakan metode Unified Model Language (UML) bertujuan untuk memodelkan suatu sistem yang dapat mudah dipahami oleh manusia maupun mesin [8]. UML yang digunakan yaitu Use Case Diagram, Class Diagram dan Activity Diagram. Use case diagram berisikan diagram penggunaan pada setiap actor atau pengguna dimana dalam kasus ini digunakan oleh dua actor yaitu penjual dan konsumen. Gambar dari Use Case diagram dapat dilihat pada Gambar 1.

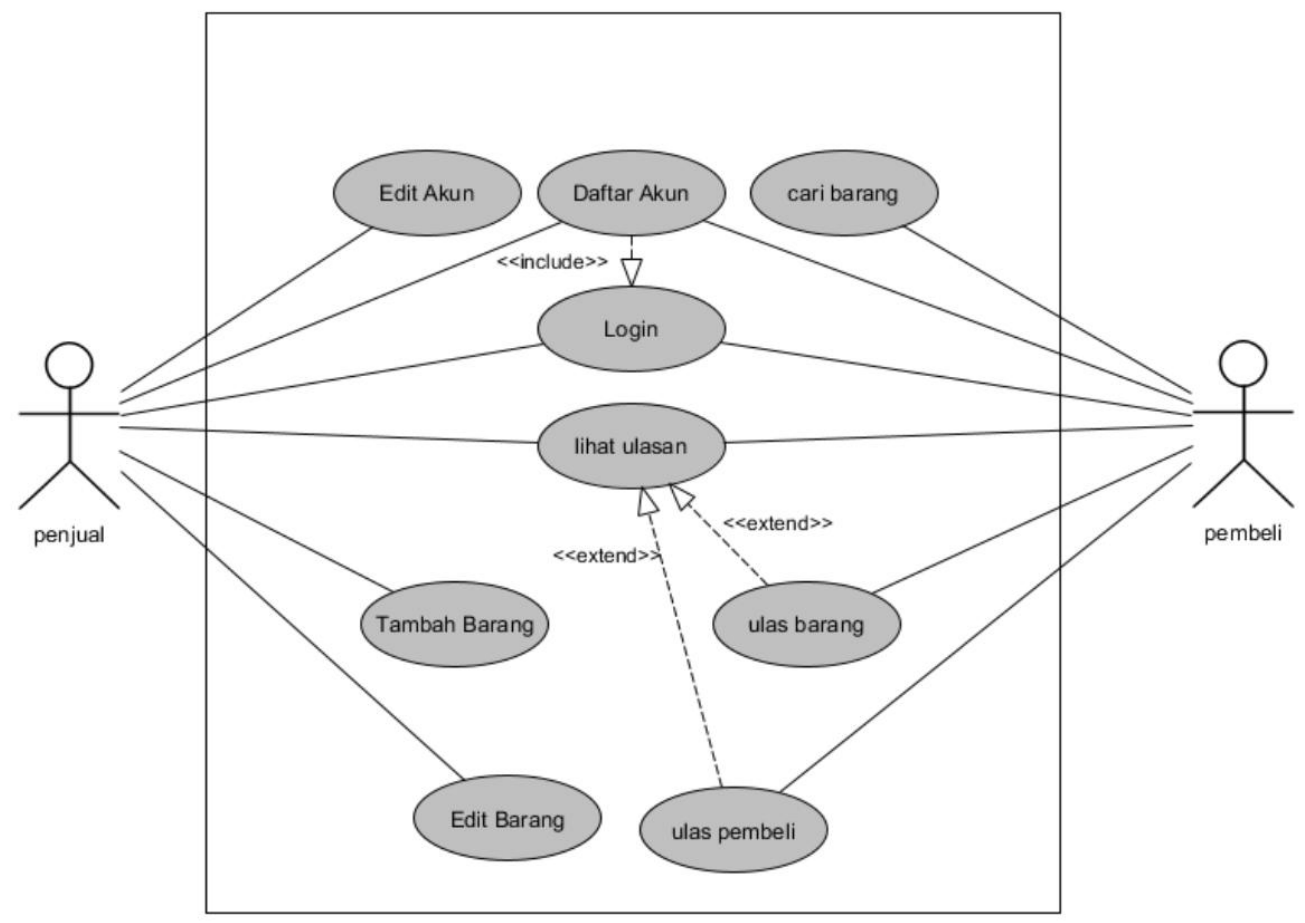

Gambar 1 Use Case Diagram Aplikasi Nawani-Nukoni

Class Diagram menggambarkan atribut, property, atau metode pada suatu abstract class beserta hubungan antar class yang lain. Pada Gambar 2 dijelaskan bahwa sistem inventaris tersebut menggunakan 5 abstract class yang mewakili masing-masing entitas yang ada, yaitu Seller, User, Item, Home Category, dan Review. 


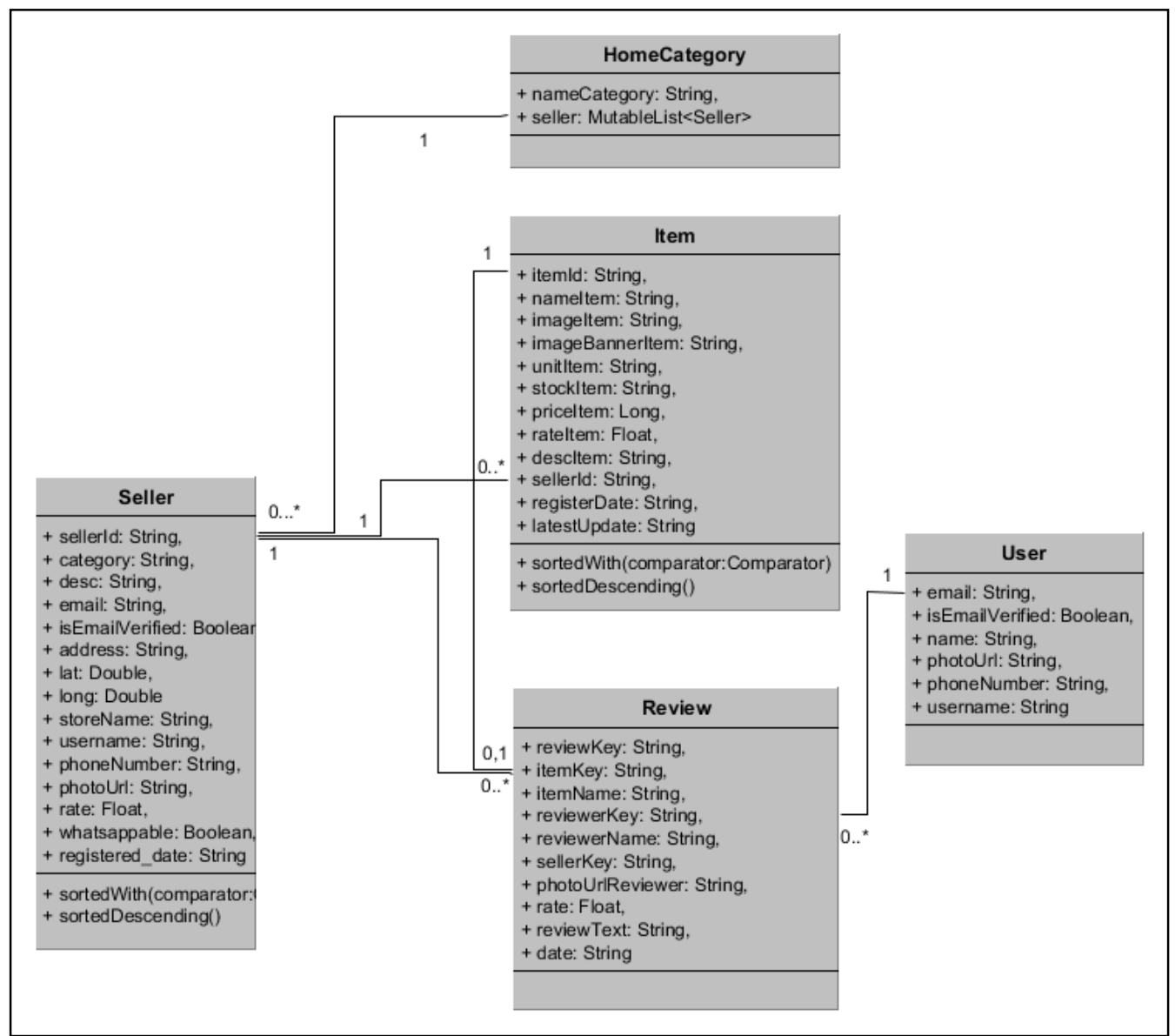

Gambar 2. Class Diagram Aplikasi Nawani-Nukoni

Activity Diagram menunjukan aktivitas penggunaan secara lengkap dari awal dimulainya sistem hingga sistem dimatikan atau ditutup. Pada Gambar 3 ditunjukan 3 activity yaitu, activity Nawani sebagai client, activity Firebase sebagai server, dan activity Nukoni sebagai client. Aplikasi Nawani yang dikhususkan kepada pelaku bisnis UMKM diimplementasikan pada smartphone Android yang dapat diunduh pada Playstore (Gambar 4). 
Nawani And Nukoni Applications for Supporting Small and Medium Micro Enterprises in Gunungkidul District

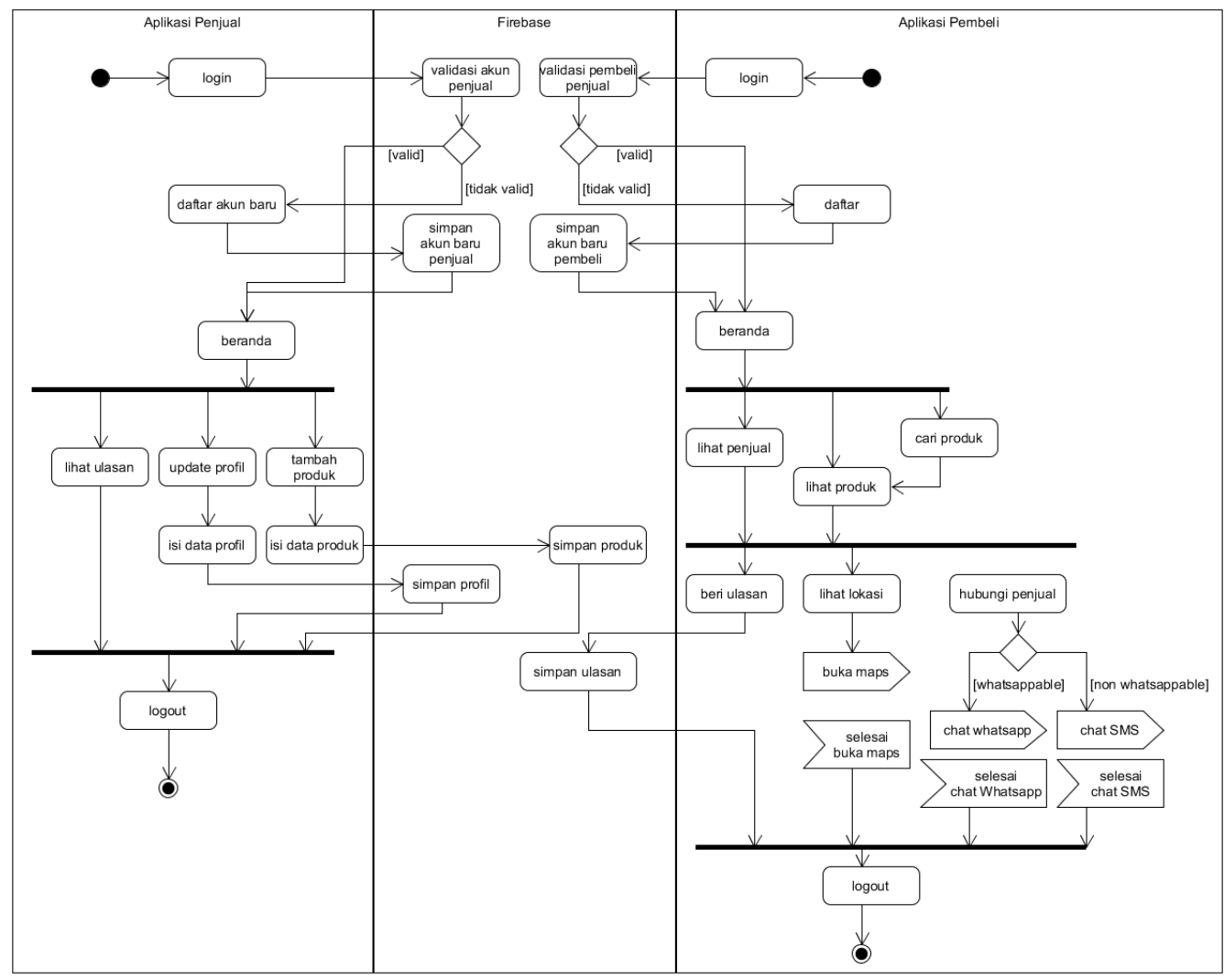

Gambar 3 Activity Diagram Aplikasi Nawani-Nukoni

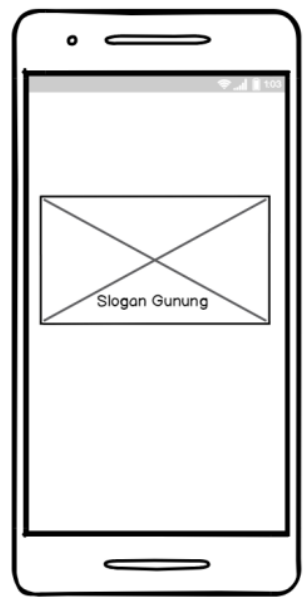

(a)

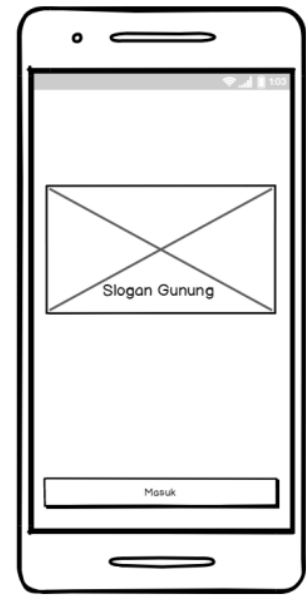

(b)

Gambar 4 Perancangan Interface Aplikasi Nawani dan Nukoni

\section{Hasil dan Pembahasan}

Hasil dari aplikasi inventaris UMKM dan Mitra UMKM yang diberi nama Nawani untuk aplikasi inventaris Mitra UMKM dapat dilihat pada Gambar 16. Sedangkan Nukoni untuk aplikasi UMKM. Kedua aplikasi tersebut di publikasikan melalui Play dtore sapat dilihat pada Gambar 5. 
Asih Pujiastuti, Astika Ayuningtyas, Anggraini Kusumaningrum, Adetya Dyas Saputra

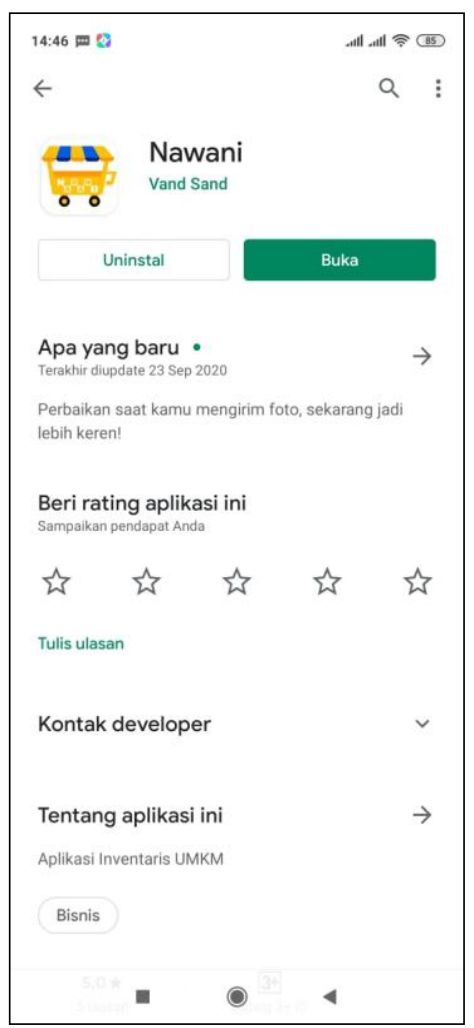

(a)

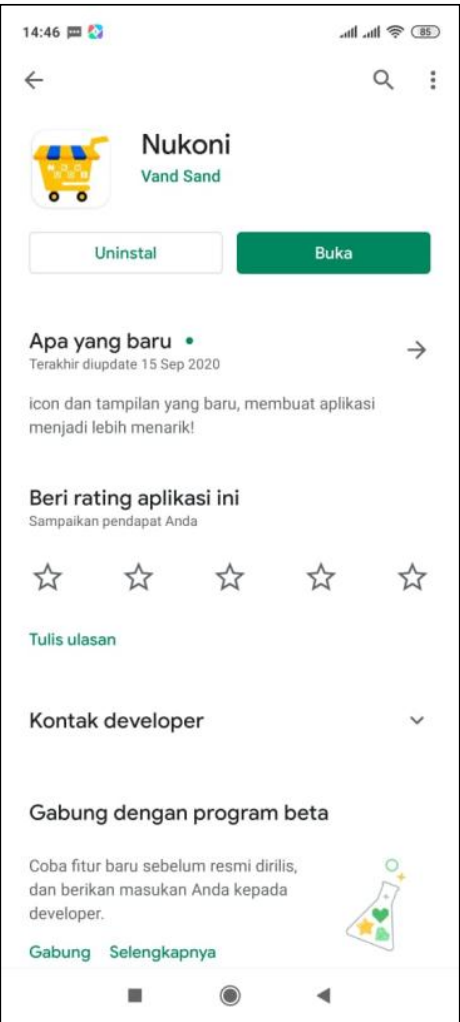

(b)

Gambar 5. Aplikasi Nawani (a) dan Nukoni (b) di Play Store

Pada Gambar 6 adalah tampilan pada detail produk, berupa informasi yang telah diberikan oleh penjual seperti gambar banner, gambar display, nama produk, harga, ukuran per satuan, serta deskripsi produk. Pada bagain bawah informasi produk terdapapat rating produk serta text button yang digunakan untuk beralih ke screen ulasan. Rating tersebut didapatkan oleh rata-rata konsumen yang memberikan ratingnya berupa angka dari 0 hingga 5 dengan step size 0.1 . Pada bagian paling bawah terdapat informasi kontak penjual yaitu nomor telepon dan alamat UMKM, kedua text tersebut berupa text button yang dapat ditekan. Apabila nomor telepon ditekan, aplikasi akan membuka aplikasi chat tergantung pada profil UMKM apakah dapat dihubungi melalui Whatsapp atau tidak. Jika iya maka akan membuka Whatsapp jika tidak akan membuka layanan SMS dengan text bawaan aplikasi dan nomor telepon yang sudah otomatis diset. Apabila alamat UMKM ditekan dan profil UMKM sudah melakukan tagging lokasi pada aplikasi, maka akan membuka Google Maps dengan titik fokus lokasi UMKM beserta nama daerah alamat yang ada pada profil UMKM, jika belum melakukan tagging lokasi maka akan muncul pesan bahwa UMKM tersebut belum mengeset lokasinya. 
Nawani And Nukoni Applications for Supporting Small and Medium Micro Enterprises in Gunungkidul District

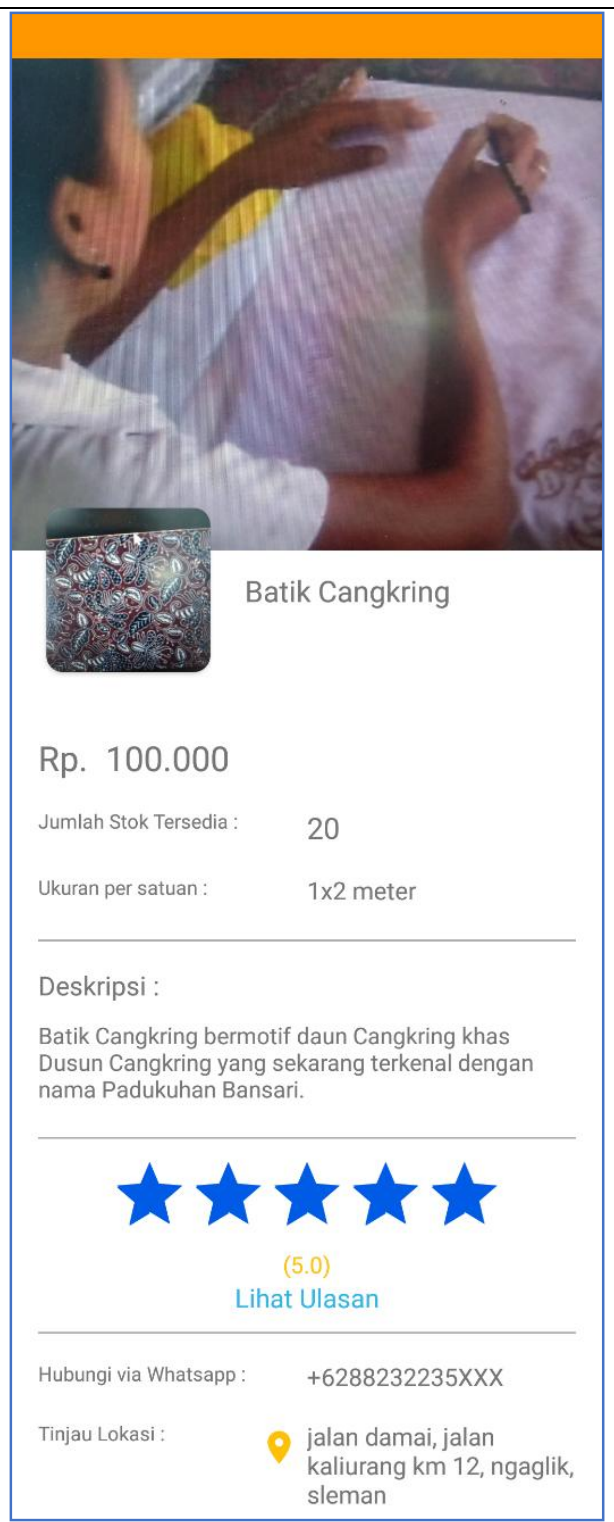

Gambar 6 Tampilan Detail Produk dari Aplikasi Nawani-Nukoni

Berdasarkan hasil pengujian yang telah dilakukan, yang terdiri dari 2 metode pengujian, yaitu uji fungsionalitas dan uji pengguna. Uji fungsionalitas dilakukan terhadap semua fungsi yang ada pada kode baris dan kecepatan transaksi, Tabel 2 dan 3 adalah cuplikan hasil pengujian pada kode baris dan Tabel 4 dan 5 adalah hasil pengujian kecepatan transfer data.

Tabel 2 Cuplikan Hasil Uji Fungsionalitas pada Baris Kode Nawani

\begin{tabular}{|c|c|c|c|c|c|}
\hline No. & fungsi & Kode baris & $\begin{array}{c}\text { Ekspektasi } \\
\text { Hasil }\end{array}$ & $\begin{array}{c}\text { Hasil } \\
\text { Pengujian }\end{array}$ & Keterangan \\
\hline 1. & Login & $\begin{array}{l}\text { protected fun signln( } \\
\text { mGoogleSignClient: } \\
\text { GoogleSignInClient) \{ } \\
\text { val signInIntent = } \\
\text { mGoogleSignClient } \\
\text {.getSignInIntent() } \\
\text { startActivityForResult( } \\
\text { signInIntent, } \\
\text { LoginActivity.RC_SIGN_IN }\end{array}$ & $\begin{array}{l}\text { Muncul Dialog } \\
\text { Email }\end{array}$ & $\begin{array}{l}\text { Muncul Dialog } \\
\text { Email }\end{array}$ & valid \\
\hline 2 & Register & $\begin{array}{l}\text { dbReference.child(FIREB } \\
\text { ASE_NawaniNukoni).child } \\
\text { (mUserUid!!).child(FIREB }\end{array}$ & $\begin{array}{l}\text { Masuk ke } \\
\text { beranda dan } \\
\text { akun }\end{array}$ & $\begin{array}{l}\text { Masuk ke } \\
\text { beranda dan } \\
\text { akun }\end{array}$ & valid \\
\hline
\end{tabular}


Asih Pujiastuti, Astika Ayuningtyas, Anggraini Kusumaningrum, Adetya Dyas Saputra

ASE NawaniNukoni PRO FILE).setValue(seller)

tersimpan ke server

tersimpan ke .addOnCompleteListener\{ startActivity<

MainActivity $>$ (EXTRA_SE

LLER to seller)

finishAffinity()

.child(FIREBASE_ITEM_N awaniNukoni).child(item.it emld).setValue(item).add OnSuccessListener LOGE("uploaded") \} .addOnCompleteListener\{ toast("Data terupdate") \}

data produk pada server dan client bertambah

data produk pada server dan client bertambah valid

Stock item

yang dipilih berubah pada client maupun server.

Stock item yang dipilih berubah pada client maupun server.

Data profil

valid

Data profil berubah pada client maupun server. server.

Valid child(FIREBASE Nawani

Nukoni)

child(FIREBASE Nawani

Nukoni PROFILE)

setValue(newSeller)

.addOnSuccessListener \{

LOGE("uploaded") \}

.addOnCompleteListener \{ toast("Data terupdate") \}

Tabel 3 Contoh Hasil Uji Fungsionalitas pada Baris Kode Nukoni

\begin{tabular}{|c|c|c|c|c|c|}
\hline \multicolumn{6}{|c|}{ Uji Fungsionalitas pada baris kode } \\
\hline No & fungsi & Kode baris & $\begin{array}{c}\text { Ekspektasi } \\
\text { Hasil }\end{array}$ & $\begin{array}{c}\text { Hasil } \\
\text { Pengujian }\end{array}$ & Keterangan \\
\hline & Login & $\begin{array}{l}\text { mGoogleSignClient: } \\
\text { GoogleSignlnClien) }\{ \\
\text { val signlnIntent = } \\
\text { mGoogleSignClient } \\
\text {.getSignInIntent() } \\
\text { startActivityForResult( } \\
\text { signInIntent, } \\
\text { LoginActivity. } \\
\text { RC_SIGN_IN) } \\
\text { \} }\end{array}$ & $\begin{array}{l}\text { Muncul Dialog } \\
\text { Email }\end{array}$ & $\begin{array}{l}\text { Muncul Dialog } \\
\text { Email }\end{array}$ & valid \\
\hline
\end{tabular}


Nawani And Nukoni Applications for Supporting Small and Medium Micro Enterprises in Gunungkidul District

\begin{tabular}{|c|c|c|c|c|c|}
\hline 2 & Register & $\begin{array}{l}\text { dbReference.child(FIRE } \\
\text { BASE_USER).child(mU } \\
\text { serUid!!).child(FIREBAS } \\
\text { E_USER_PROFILE) } \\
\text {.setValue(user) } \\
\text {.addOnSuccessListener } \\
\text { \{ LOGE("uploaded") \} } \\
\text {.addOnCompleteListene } \\
\mathrm{r}\{ \\
\text { startActivity<MainActivit } \\
\begin{array}{l}\mathrm{y}>() \\
\text { finishAffinity() }\end{array} \\
\text { \} }\end{array}$ & $\begin{array}{l}\text { Data akun baru } \\
\text { bertambah pada } \\
\text { client lalu } \\
\text { menuju beranda. }\end{array}$ & $\begin{array}{l}\text { Data akun } \\
\text { baru } \\
\text { bertambah } \\
\text { pada client } \\
\text { lalu menuju } \\
\text { beranda. }\end{array}$ & Valid \\
\hline 3 & $\begin{array}{l}\text { Mereview } \\
\text { barang }\end{array}$ & $\begin{array}{l}\text { dbReference } \\
\text {.child(FIREBASE_ITEM } \\
\text { REVIEW) } \\
\text {.child(newReview.revie } \\
\text { wKey) } \\
\text {.setValue(newReview) } \\
\text {.addOnSuccessListener } \\
\{\text { LOGE("uploaded") \} } \\
\text {.addOnCompleteListene } \\
\text { r\{ toast("Data } \\
\text { terupdate") \} }\end{array}$ & $\begin{array}{l}\text { Review berhasil } \\
\text { bertambah pada } \\
\text { client maupun } \\
\text { server }\end{array}$ & $\begin{array}{l}\text { Review } \\
\text { berhasil } \\
\text { bertambah } \\
\text { pada client } \\
\text { maupun } \\
\text { server }\end{array}$ & valid \\
\hline 4 & $\begin{array}{l}\text { Pencarian } \\
\text { Produk }\end{array}$ & 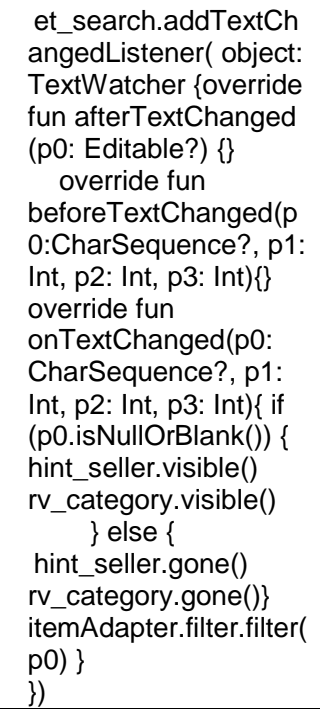 & $\begin{array}{l}\text { Muncul produk } \\
\text { sesuai katakunci } \\
\text { serta menutup } \\
\text { bagian UMKM }\end{array}$ & $\begin{array}{l}\text { Muncul produk } \\
\text { sesuai } \\
\text { katakunci } \\
\text { serta menutup } \\
\text { bagian UMKM }\end{array}$ & Valid \\
\hline
\end{tabular}


Asih Pujiastuti, Astika Ayuningtyas, Anggraini Kusumaningrum, Adetya Dyas Saputra

\begin{tabular}{|c|c|c|c|c|c|}
\hline 5 & $\begin{array}{l}\text { Mengambil data } \\
\text { detail produk }\end{array}$ & $\begin{array}{l}\text { sellerRef.addValueEv } \\
\text { entListener (object: } \\
\text { ValueEventListener } \\
\text { \{erride fun } \\
\text { onCancelled(p0: } \\
\text { DatabaseError)\{ } \\
\text { \} } \\
\text { override fun } \\
\text { onDataChange(p0: } \\
\text { DataSnapshot)\{ } \\
\text { if (p0.exists()) \{ } \\
\text { mitra = } \\
\text { p0.getValue(Seller::cla } \\
\text { ss.java) as Seller } \\
\text { itemBinding (mitra) } \\
\text { \}else \{ } \\
\text { toast( getString( } \\
\text { R.string.general_error, } \\
\text { "DIA76"))\}\} } \\
\text { \}) }\end{array}$ & $\begin{array}{l}\text { Data dari server } \\
\text { ditampilkan dan } \\
\text { dipasang } \\
\text { (binding) }\end{array}$ & $\begin{array}{l}\text { Data dari } \\
\text { server } \\
\text { ditampilkan } \\
\text { dan dipasang } \\
\text { (binding) }\end{array}$ & valid \\
\hline
\end{tabular}

Uji Fungsionalitas yang dilakukan dengan menggunakan source code menunjukan bahwa 5 dari 5 cuplikan source code berdasarkan fitur utama aplikasi Nawani maupun Nukoni berjalan dengan baik.

Tabel 4 Hasil Uji Fungsionalitas pada Kecepatan Transfer Data Nawani

\begin{tabular}{|c|c|c|c|c|c|}
\hline \multirow[b]{2}{*}{ No } & \multirow[b]{2}{*}{ Provider } & \multirow[b]{2}{*}{ Ping (ms) } & \multicolumn{3}{|c|}{ Kecepatan (ms) } \\
\hline & & & Daftar & $\begin{array}{l}\text { Tambah } \\
\text { Produk }\end{array}$ & Update Stok \\
\hline 1 & $\begin{array}{l}\text { WIFI TELKOM - PT. Telekomunikasi } \\
\text { Indonesia }\end{array}$ & 4 & 1022 & 695 & 334 \\
\hline 2 & 3 - PT. Hutchison 3 Indonesia & 24 & 1031 & 808 & 372 \\
\hline $\begin{array}{l}3 \\
4\end{array}$ & $\begin{array}{l}\text { Telkomsel - PT Telekomunikasi } \\
\text { Selular Indonesia }\end{array}$ & 59 & 1054 & $\begin{array}{l}156 \\
937\end{array}$ & $\begin{array}{l}658 \\
660\end{array}$ \\
\hline 5 & Smartfren - PT. Smartfren Telecom & 80 & 990 & 881 & 636 \\
\hline
\end{tabular}

Tabel 5 Hasil Uji Fungsionalitas pada Kecepatan Transfer Data Nawani

\begin{tabular}{|c|c|c|c|c|}
\hline \multirow[b]{3}{*}{ no } & \multicolumn{4}{|c|}{ Uji Fungsionalitas pada kecepatan transfer data } \\
\hline & \multirow[b]{2}{*}{ provider } & \multirow{2}{*}{ Ping (ms) } & \multicolumn{2}{|c|}{ Kecepatan (ms) } \\
\hline & & & daftar & review \\
\hline 1 & $\begin{array}{l}\text { WIFI TELKOM - PT. Telekomunikasi } \\
\text { Indonesia }\end{array}$ & 4 & 332 & 368 \\
\hline 2 & 3 - PT. Hutchison 3 Indonesia & 24 & 367 & 412 \\
\hline 3 & Smartfren - PT. Smartfren Telecom & 80 & 398 & 552 \\
\hline 4 & IM3 Ooredoo - PT INDOSAT Tbk & 41 & 534 & 593 \\
\hline 5 & $\begin{array}{l}\text { Telkomsel - PT Telekomunikasi } \\
\text { Selular Indonesia }\end{array}$ & 59 & 700 & 491 \\
\hline
\end{tabular}

Pengujian yang dilakukan dengan menganalisis kecepatan transfer data dari client server tergolong cepat karena seluruh pengujian fitur utama memiliki kecepatan transfer rata-rata kurang dari 1 detik $(667,52$ ms. Uji Pengguna dilakukan terhadap aplikasi langsung terhadap pengguna untuk mendapatkan User Experience dan baik dari segi cara penggunaan maupun device pengguna dalam berbagai kondisi. Uji pengguna dilakukan menggunakan kuisioner yang dibagi menjadi 3 bagian, yaitu bagian informasi pengguna dan device, bagian fungsi aplikasi, dan bagian User Interface/User Experience (UI/UX), hasil dari pengujian ini terlihat pada Tabel 4 dan 5. 
Nawani And Nukoni Applications for Supporting Small and Medium Micro Enterprises in Gunungkidul District

Tabel 4 Hasil Uji Pengguna oleh Pelaku Bisnis UMKM

\begin{tabular}{|c|c|c|c|c|}
\hline Nama Toko yang didaftarkan & $\begin{array}{l}\text { Total Bobot } \\
\text { Uji Fungsi }\end{array}$ & $\begin{array}{c}\text { Total Bobot } \\
\text { Uji UI/UX }\end{array}$ & $\begin{array}{l}\text { Hasil Persentase } \\
\text { Uji Fungsi }(\%)\end{array}$ & $\begin{array}{l}\text { Hasil Persentase } \\
\text { Uji UX/UX (\%) }\end{array}$ \\
\hline Emping melinjo barokah & 15 & 44 & 75 & 88 \\
\hline Gallery 99 Metal art & 18 & 38 & 90 & 76 \\
\hline Snack 234 & 15 & 38 & 75 & 76 \\
\hline Elega Perca & 15 & 31 & 75 & 62 \\
\hline KWT "SALAM MAJU" & 15 & 39 & 75 & 78 \\
\hline Pop cron & 20 & 40 & 100 & 80 \\
\hline Cripang & 15 & 39 & 75 & 78 \\
\hline crian & 15 & 40 & 75 & 80 \\
\hline Wagiyen & 15 & 12 & 75 & 24 \\
\hline Makmur barokah & 14 & 36 & 70 & 72 \\
\hline Toko kartika & 11 & 36 & 55 & 72 \\
\hline Makmur barokah & 14 & 36 & 70 & 72 \\
\hline Bantal Dakron & 15 & 37 & 75 & 74 \\
\hline Mbak wiek & 15 & 20 & 75 & 40 \\
\hline DEASY ORCHID & 20 & 40 & 100 & 80 \\
\hline Wesi Aji Argo Wijil & 19 & 45 & 95 & 90 \\
\hline Panji sejati & 13 & 38 & 65 & 76 \\
\hline supri sangkar & 19 & 37 & 95 & 74 \\
\hline Soreng Barokah & 15 & 38 & 75 & 76 \\
\hline Mbak wiek & 15 & 20 & 75 & 40 \\
\hline jejamuan barokah & 15 & 35 & 75 & 70 \\
\hline Jaka Samudro & 15 & 38 & 75 & 76 \\
\hline Joyo Noto Ornamen & 15 & 23 & 75 & 46 \\
\hline Dewata & 20 & 49 & 100 & 98 \\
\hline Minyak atsiri & 15 & 30 & 75 & 60 \\
\hline Mebel primitif & 15 & 29 & 75 & 58 \\
\hline Niki eco & 12 & 28 & 60 & 56 \\
\hline Joko samudro & 17 & 36 & 85 & 72 \\
\hline Barokah Katering & 20 & 30 & 100 & 60 \\
\hline sarniyati & 16 & 42 & 80 & 84 \\
\hline
\end{tabular}

Tabel 5 Hasil Uji Pengguna oleh Konsumen (Masyarakat)

\begin{tabular}{lcccc}
\hline \multicolumn{1}{c}{$\begin{array}{c}\text { Nama yang digunakan saat } \\
\text { mendaftar }\end{array}$} & $\begin{array}{c}\text { Total Bobot } \\
\text { Uji Fungsi }\end{array}$ & $\begin{array}{c}\text { Total Bobot } \\
\text { Uji UI/UX }\end{array}$ & $\begin{array}{c}\text { Hasil Persentase } \\
\text { Uji Fungsi }(\%)\end{array}$ & $\begin{array}{c}\text { Hasil Persentase } \\
\text { Uji UX/UX (\%) }\end{array}$ \\
\hline Pranawesta Devano & 24 & 45 & 75 & 90 \\
Dwinny Puspa DS & 30 & 37 & 93,75 & 74 \\
Arifin & 24 & 30 & 75 & 60 \\
Ersa elfiyanto & 32 & 45 & 100 & 90 \\
Sofyan & 28 & 37 & 87,5 & 74 \\
Sukisni & 24 & 39 & 75 & 78 \\
Endang sri lestari & 20 & 39 & 62,5 & 78 \\
Wagiyen & 24 & 11 & 75 & 22 \\
Tri sutarti & 32 & 39 & 100 & 78 \\
ernawati & 32 & 40 & 100 & 80 \\
Sukisni & 24 & 39 & 75 & 78 \\
Daliyah & 24 & 39 & 75 & 78 \\
Sri yuntari & 38 & 75 & 76 \\
Anna & 24 & 44 & 100 & 88 \\
Nur ali muchtarom & 32 & 33 & 81,25 & 66 \\
Raden & 26 & 36 & 93,75 & 72 \\
sayoga & 30 & 26 & 75 & 52 \\
Arita & 24 & 36 & 100 & 72 \\
Enoge & 32 & 30 & 75 & 60 \\
Diky & 24 & 30 & 96,875 & 76 \\
Agung & 31 & 75 & 60
\end{tabular}


Asih Pujiastuti, Astika Ayuningtyas, Anggraini Kusumaningrum, Adetya Dyas Saputra

\begin{tabular}{llccc}
\hline Mr zae & 24 & 30 & 75 & 60 \\
Arf legend & 23 & 34 & 71,875 & 68 \\
Irfan & 24 & 30 & 75 & 60 \\
Adi Suryantoro & 24 & 30 & 75 & 60 \\
Asrofi & 24 & 29 & 75 & 58 \\
Deno D. Cessara & 32 & 40 & 100 & 80 \\
yasifa & 23 & 38 & 71,875 & 76 \\
Rezky & 31 & 37 & 96,875 & 74 \\
Agus Saputra & 32 & 34 & 100 & 68 \\
\hline
\end{tabular}

Aplikasi Nawani pada Uji Fungsi sebesar 78,8\% dan Uji UI/UX sebesar 69,6\% sehingga aplikasi Aplikasi Nukoni termasuk dalam skala bahwa aplikasi berjalan tanpa kendala dan memiliki tampilan menarik. Sedangkan skor dari Aplikasi Nukoni pada Uji Fungsi sebesar 85,3\% dan Uji UI/UX sebesar 70,2\% sehingga Aplikasi Nawani termasuk dalam skala bahwa aplikasi berjalan tanpa kendala dan memiliki tampilan menarik.

\section{Kesimpulan}

Berdasarkan perancangan, implementasi dan pengujian pada Aplikasi Nawani dan Nukoni, dapat diambil beberapa kesimpulan:

a. Berdasarkan pengujian secara fungsional, Aplikasi Nukoni dan Nawani berjalan lancar karena 5 dari 5 cuplikan pengujian fitur utama berjalan lancar

b. Berdasarkan pengujian secara langsung oleh pengguna, Aplikasi Nukoni dan Nawani cocok digunakan oleh pelaku bisnis UMKM dan konsumen di daerah Gunungkidul serta memiliki tampilan yang menarik.

c. Berdasarkan pengujian fungsional dengan kecepatan transfer data, Aplikasi Nukoni dan Nawani memiliki kemampuan transfer yang cepat karena rata-rata kecepatan mencapai 667, 52 ms.

\section{Daftar Pustaka}

[1] Dictionary.(2018). mobile. [Online] Tersedia di:https://www.dictionary.com/browse/mobile [Diakses 2 Agustus 2019]

[2] Wardhana, L., \& Makodian, N. (2010). Teknologi Wireless Communication dan Wireless Broadband. Penerbit Andi.

[3] Ayuningtyas, A., Yuliani, I., \& Uyunul, M. (2020). Promotion System for Promotional Products and Tourist Object in Patuk Gunungkidul District. Angkasa: Jurnal Ilmiah Bidang Teknologi, 12(1), 79-88.

[4] Suci, Y. R. (2017). Perkembangan UMKM (Usaha mikro kecil dan menengah) di Indonesia,Cano Ekonomos, 6(1), 51-58.

[5] Firebase.(2017). Realtime Database.[Online] Tersedia di https://firebase.google.com/docs/database [Diakses 2 Agustus 2019].

[6] Albertengo, G., Fikru, G.D., Waqar, H., Dario, S. (2019, February). On the performance of web services, google cloud messaging andfirebasecloud messaging. Journal Digital Communication and Networks, 6(2020), 31-37. doi:10.1016/j.dcan.2019.02.002.

[7] Ohyver, M., Jurike, V.M., Iwa, S., Bonifasius, E.S., Ian, A. C. (2019, September). The Comparison Firebase Realtime Database and MySQL Database Performance using Wilcoxon Signed-Rank Test. Journal Procedia Computer Science, 157(2020), 396-405. doi: 10.1016/j.procs.2019.08.231.

[8] Jacobson, I., Booch, G., \& Rumbaugh, J. (1996). The Unified Modeling Language. University Video Communications. 